\title{
Fertility Behaviour and Effect of Son Preference among the Muslims of Manipur, India
}

\author{
Mohammad Asghar, ${ }^{1}$ Benrithung Murry, ${ }^{2}$ and Kallur Nava Saraswathy ${ }^{2}$ \\ ${ }^{1}$ Department of Anthropology, Rajiv Gandhi University, Itanagar 791112, India \\ ${ }^{2}$ Department of Anthropology, University of Delhi, Delhi 110007, India \\ Correspondence should be addressed to Mohammad Asghar; asghar2108@gmail.com
}

Received 30 May 2014; Revised 11 August 2014; Accepted 11 August 2014; Published 26 August 2014

Academic Editor: Kaushik Bose

Copyright (C) 2014 Mohammad Asghar et al. This is an open access article distributed under the Creative Commons Attribution License, which permits unrestricted use, distribution, and reproduction in any medium, provided the original work is properly cited.

Fertility is one of the most important components of demographic studies affecting almost all aspects of human life. Present paper is an attempt to study various factors, including preference of son, affecting the fertility of Manipuri Muslims. A household survey was conducted in Imphal East and Thoubal districts where the concentration of Muslim is found to be the highest, interviewing 512 ever married women. Age at marriage, age at first conception, education, occupation, types of family, and per capita annual income are influencing the fertility rate among this population. Uses of birth control measures, consanguineous marriage, and age at menarche have no effect on fertility rate. The preference for more sons is observed in this study leading to increase in overall fertility rate.

\section{Introduction}

Fertility is the only way for biological replacement of human being in order to continue its existence on earth. If the human society is to prevail, it is through fertility only as one cannot control death. That is why, of the three main aspects of demography, fertility, mortality, and migration, fertility always occupies a central position in population study. However, in the last few decades, because of the exponential growth in human population with limited natural resource available, there arises a common concern not to take full advantage of human fertility. At the same time, fertility is not free from biological and social or environmental factors. The fertility rate of any population is always influenced by various factors, directly or indirectly. The degree of influence of these factors on fertility may differ from population to population or from society to society. Age at menarche, age at menopause, age at marriage, age at first conception, per capita annual income, education, and occupation are some of the factors which has been extensively studied. Parents' preference of son over daughter is also one of the important factors affecting fertility prevail in many communities. It has become a key hindrance in controlling population growth in many under developed and developing countries like India [1-5]. The notion of preference is further influenced by the perceptions and social values attached to the different genders by the society itself [6-8]. This preference of son ultimately affects the demographic behaviour. It may either reduce the sex ratio by a cruel practice of female infanticide or increase the total fertility rate beyond the expectation while trying to get more sons. In India, where there is strict law on female infanticide the latter is more likely to happen. However, in both ways skewed sex ratio may result. The present study is an attempt to determine various biological and social factors including son preference influencing fertility among one of the endogamous population, Manipuri Muslims.

\section{Material and Methods}

Manipuri Muslims are an endogamous community inhabiting mainly in the valley of Manipur with a population 
size of $\sim 200,000$ [9], $8 \%$ of the total population. They are scattered all over the state with the highest concentration in Imphal East and Thoubal districts constituting $~ 87 \%$ of the total Manipuri Muslim population. They follow strict matting pattern with community endogamy and clan exogamy [10]. The socioeconomic condition of Manipuri Muslims is in general poor with majority of the households fetching less than Rs. 2000/- per month per household [11]. The literacy rate, according to census 2001 [9], is found to be $58.6 \%$ as against state's $70.5 \%$.

Two districts, Imphal East and Thoubal, were found to have the highest concentrations of Muslims and therefore these two districts were selected for this study. A questionnaire/schedule was framed and tested before applying to the field. A household survey was conducted interviewing a total of 512 ever married women from these two districts. Proper consents were taken before starting the interview after making them to understand the purpose and benefit of the study. Interviews were conducted in isolation in order to maintain privacy and in free-frank manner. Information related to reproductive profile, education, occupation, per capita annual income, and birth control measures was collected with most possible accuracy. Some of the doubted information were verified and confirmed from their spouse. Descriptive analysis, stepwise linear regression, correlation, and $t$-test were performed. Statistical significance was checked at 5\% level of probability.

\section{Result and Discussion}

The results of the present study were discussed with relevant tables. The crude birth rate in the present study is calculated as 22.73 per 1000 population, similar to that of India's 22.8 [12] but higher from the total Manipur's 15.8 [12]. However, the total fertility rate in the present study (2.44) is lower than that of India's 3.8 (2001 census) but similar to Manipur's 2.4 [9]. The mean number of conception is calculated as 6.73 and mean number of live birth as 5.97 which is lower than the earlier reports on the same population, 7.84 [13] and 6.39 [14], respectively.

3.1. Factors Affecting Fertility. Various biological and social factors were examined in order to understand their effect on fertility. Age at menarche is an important factor that affects the childbearing period and hence fertility. However, it does not give any significant effect on fertility in this study (Table 1). The mean live birth does not show any relation with the age at menarche. The mean age at menarche in present study is 12.86 years. The mean age at menarche varies from population to population and it is known to be influenced by a number of factors like environment, altitude of place, socioeconomic status and genetic factors, and so forth [1517]. Comparing with earlier reports it is shown that the mean age at menarche among Manipuri Muslims become lower from 14.4 years [14]. It is also lower than that of the neighbouring populations like Tangkhul Naga (13.93), Kabui (15.15) [18], Meitei (13.6), Kabui (15.4), and Nepalese (14.03) [14]. The "secular trend" observed in this study is probably an
TABLE 1: Fertility of Muslim women based on age at menarche.

\begin{tabular}{lccc}
\hline $\begin{array}{l}\text { Age at } \\
\text { menarche } \\
\text { (year) }\end{array}$ & Woman (\%) & Mean conception & $\begin{array}{c}\text { Mean live } \\
\text { birth }\end{array}$ \\
\hline 9 & 0.19 & 1.00 & 0.00 \\
10 & 1.56 & 3.87 & 2.88 \\
11 & 4.88 & 4.00 & 3.20 \\
12 & 38.08 & 3.92 & 3.28 \\
13 & 30.27 & 3.88 & 3.33 \\
14 & 14.06 & 4.60 & 3.76 \\
15 & 8.98 & 3.35 & 2.72 \\
16 & 0.98 & 3.20 & 2.60 \\
17 & 0.98 & 2.80 & 3.20 \\
\hline Total & 100 & 3.95 & 3.29 \\
\hline
\end{tabular}

outcome of better nutrition and improved living condition in the last decade.

Age at marriage and age at first conception are two direct factors that influence fertility. The mean age at marriage among Manipuri Muslims in the present study (18.57 years) is higher compared to the earlier reports on the same population, 16.4 years [13] and 17.54 years [14]. This is a positive indication which might help in decreasing the fertility rate. However, it is still lower than that of Meitei (19.98 years) and Kabui (20.03 years) [14]. Table 2 shows that the highest mean number of conception (6.09) and live birth (5) is found at the age group less than 15 years. Both conception and live birth gradually decreased with increase in age, least falling at the age cohort 30-34 years (mean conception $=3$; mean live birth $=$ 2). This clearly indicates that the number of conception and live birth among Muslim women has an inverse relationship with age at marriage.

Age at first conception is more important than the age at marriage in determining the fertility. In the present study, mean age at marriage and mean age at first conception are almost similar indicating women are conceived almost immediately after marriage. It is generally observed that age at first conception is inversely related to the fertility. The mean age at first conception is 18.96 years which is almost similar to the earlier reports on this population, 18.01 years [13] and 18.66 years [14]. However, the mean is lower than the other neighbouring populations: 20.96 years among Meitei, 22.87 years among Kabui, and 20.16 years among Nepalese [14].

It has been found that $96.19 \%$ of all Muslim women had their first conception before the age of 25 years. Of all the pregnancies, $2.21 \%$ women conceived for the first time before the age of 15 years, and only $3.81 \%$ women were above 24 years at time of their first conception (Table 2). The mean number of conception (6.09) and live birth (5.00) is found to be the highest at the age cohort less than 15 years and both mean numbers of conception and live birth decreased with the increase of age at first conception. This indicates the inverse relationship between age at first conception and fertility. 
TABLE 2: Association of age at marriage and age at first conception with fertility.

\begin{tabular}{|c|c|c|c|c|c|c|}
\hline \multirow{2}{*}{ Age cohort } & \multicolumn{3}{|c|}{ Association of age at marriage with fertility } & \multicolumn{3}{|c|}{ Association of age at 1st conception with fertility } \\
\hline & Woman (\%) & Mean conception & Mean live birth & Woman* $(\%)$ & Mean conception & Mean live birth \\
\hline$<15$ & 2.15 & 6.09 & 5.00 & 2.21 & 6.09 & 5.00 \\
\hline $15-19$ & 61.91 & 4.20 & 3.56 & 59.44 & 4.34 & 3.70 \\
\hline $20-24$ & 33.59 & 3.50 & 2.82 & 34.54 & 3.59 & 2.92 \\
\hline $25-29$ & 2.15 & 1.91 & 1.36 & 3.01 & 2.73 & 1.73 \\
\hline $30-34$ & 0.20 & 3.00 & 2.00 & 0.40 & 5.50 & 2.00 \\
\hline$>34$ & 0 & 0.00 & 0.00 & 0.40 & 2.00 & 1.00 \\
\hline Total & 100 & 3.95 & 3.29 & 100 & 3.95 & 3.29 \\
\hline
\end{tabular}

${ }^{*} 14$ ever married women have not yet conceived and are excluded from calculating mean conception and mean live birth related to age at first conception.

TABLE 3: Association of education, occupation, PCAI, family type, BCM, and type of marriage with fertility.

\begin{tabular}{|c|c|c|c|c|}
\hline & Women (\%) & Mean conception & Mean live birth & $P$ value for $t$-test \\
\hline \multicolumn{5}{|l|}{ Education } \\
\hline Illiterate & 44.53 & 4.77 & 3.99 & \multirow{2}{*}{0.00081} \\
\hline Literate & 55.47 & 3.30 & 2.73 & \\
\hline \multicolumn{5}{|l|}{ Occupation } \\
\hline Housewife & 90.23 & 4.01 & 3.32 & \multirow{2}{*}{0.27} \\
\hline Working & 9.77 & 3.44 & 2.98 & \\
\hline \multicolumn{5}{|l|}{ PCAI (Rs) } \\
\hline$<10000$ & 23.83 & 4.97 & 4.43 & \\
\hline 10000-19999 & 49.02 & 3.98 & 3.23 & \\
\hline 20000-29999 & 19.73 & 3.15 & 2.56 & \\
\hline 30000-39999 & 6.25 & 2.78 & 2.06 & \\
\hline $40000+$ & 1.17 & 2.00 & 1.33 & \\
\hline \multicolumn{5}{|l|}{ Family type } \\
\hline Nuclear & 71.29 & 4.39 & 3.68 & \multirow{2}{*}{0.0001} \\
\hline Joint/extended & 29.71 & 2.86 & 2.32 & \\
\hline \multicolumn{5}{|l|}{$\mathrm{BCM}$} \\
\hline User & 20.12 & 4.54 & 3.52 & \multirow{2}{*}{0.094} \\
\hline Nonuser & 79.88 & 3.80 & 3.23 & \\
\hline \multicolumn{5}{|l|}{ Type of marriage } \\
\hline Nonconsanguineous & 94.14 & 4.00 & 3.34 & \multirow{2}{*}{0.033} \\
\hline Consanguineous & 5.86 & 3.17 & 2.50 & \\
\hline
\end{tabular}

PCAI: Per capita annual income; BCM: birth control measures.

TABLE 4: Stepwise regression analysis of factors influencing fertility among Manipuri Muslims.

\begin{tabular}{lccc}
\hline Factors & $R$ square & Standard error & $P$ value \\
\hline Per capita annual income & 0.114 & \pm 1.93 & 0.000 \\
Age at first conception & 0.185 & \pm 1.85 & 0.000 \\
Type of marriage & 0.251 & \pm 1.78 & 0.000 \\
Education & 0.295 & \pm 1.73 & 0.000 \\
\hline
\end{tabular}

Education and occupational status of mother are important social factors that affect fertility. Mostly, educated women marry late because of their educational and professional careers and they are also conscious of having a limited family size. Moreover, it is usually seen that those engaged in mental work have less number of children, as compared to those who do some sort of physical labour [19]. In the present study, $44.53 \%$ of the Manipuri Muslim women are found to be illiterate. Among the $55.47 \%$ of literate women, $20.11 \%$ attained only up to primary, $31.84 \%$ attained secondary, and $2.54 \%$ women attained up to higher secondary level of education. Only $0.98 \%$ women were found to have attained graduate and above.

The impact of education on fertility is clearly seen as $53.75 \%$ and $54.09 \%$ of conception and live birth, respectively, are contributed by the illiterate section of mother $(44.53 \%)$. Correspondingly, the mean number of conception and live birth is higher among the illiterate women (4.77 and 3.99, respectively) compared to that of the literate women (3.30 and 2.73 , respectively) (Table 3 ). The difference is also statistically significant with $P$ value of 0.00081 . Similar findings were also reported earlier on the same population $[13,14]$. 
TABLE 5: Preference of son and its association with fertility.

\begin{tabular}{|c|c|c|c|}
\hline Number of sons in first two live births & Mean live birth & Number of daughters in first two live births & Mean live birth \\
\hline 0 & 6.5 & 0 & 5.0 \\
\hline 1 & 6.3 & 1 & 6.0 \\
\hline \multirow[t]{2}{*}{2} & 5.0 & 2 & 7.0 \\
\hline & & Pearson correlation & $P$ value \\
\hline \multicolumn{2}{|c|}{ Number of sons in first two LB } & -0.002 & 0.493 \\
\hline \multicolumn{2}{|c|}{ Number of daughters in first two LB } & 0.125 & 0.099 \\
\hline
\end{tabular}

It is observed in Table 3 that most ever married Muslim women are confined in their houses as housewife (90.23\%) while only $9.77 \%$ are under working group. The occupational status of Manipuri Muslim women appears to be influenced by the tradition of Islam, where women are not preferred working outside their homes. Or it may be the result of poor educational condition of women. As expected, the mean number of conception and mean number of live birth are higher among housewife (4.01 and 3.32, respectively) compared to working group (3.44 and 2.98, respectively). However, the difference is not statistically significant $(P=$ 0.27).

In this study the economic status of the Manipuri Muslims is divided into five arbitrary groups based on per capita annual income (PCAI) (Table 3). The highest mean number of conception and live birth is observed in the category of less than Rs.10,000 PCAI. Mean number of live birth and mean number of conception decreased with the increase of PCAI. So, an inverse relationship is observed between PCAI and fertility. Thus, this study supports the observation put forward by Rao [20] and Mukhopadhyay [21] that high income is commonly associated with low fertility and on the other hand women of poorer group have greater number of children [22].

Type of the family also affects the total fertility in the present study (Table 3). It is observed that mean number of conception and mean live birth are higher among the nuclear family (4.39 and 3.68, respectively) compared to joint/extended family (2.86 and 2.32, respectively). The difference is also statistically significant with $P$ value 0.0001 .

From Table 3 it is also seen that only $20.12 \%$ of Manipuri Muslim women used birth control measures (BCM). The finding is similar to the earlier report on the same population where $14.63 \%$ used BCM compared to $49.5 \%$ among Meitei, 24.68\% among Kabui, and 31.17\% among Nepalese of Manipur [14]. Use of BCM has no effect on fertility in this study. On the contrary, user has higher mean conception and mean live birth compared to nonuser. Such a situation was also observed among Kolams of Andhra Pradesh where users were found to have a significant higher fertility [23]. Thus, it can be inferred that BCM, which is believed to be a reliable policy of curbing fertility, does not seem to have an effect on fertility of the Manipuri Muslims. This could be explained by two reasons: first, low literacy level among Muslims woman as discussed earlier and second, denunciation of birth control measures in the conservative
Islamic religious teachings which is also in concordance with observed low percentage of BCM user in the present study.

Consanguineous marriage is found among only $5.86 \%$ in the present population. This does not seem to have significant effect towards fertility. Thought the difference in mean live birth is statistically significant, the higher mean live birth and mean conception is observed among the nonconsanguineous marriage (Table 3). Stepwise regression analysis shows that per capita annual income, age at first conception, type of marriage, and education have a significant influence on fertility. It is also clearly reflects that $29.5 \%$ of the total fertility is explained by these factors (Table 4).

3.2. Son Preference and Fertility. To assess the effect of son preference on fertility, the gender of first two live births for those women who have completed their fertility were considered. Table 5 shows the preference of son and its effect on total fertility. It is observed that the total mean live birth decreased with the increase in the number of son in first two live births. The couples having not a single son in their first two live births show the highest mean live birth (6.5). It decreases to 5.0 when the couples get sons in all the first two live births. On the contrarily, the total number of live birth increased with the increase in the number of daughter in the first two live births. Couples with daughters in both their first two live births have the mean live birth of 7.0 but it reduces to 5.0 when the couples have not a single daughter in their first two live births. This shows that, in an effort to have sons, many couples continue to have children after achieving their desired family size among Manipuri Muslims which ultimately increases the total fertility rate. Pearson correlation statistic is applied to see the extant of this relationship. This observation is supported by Pearson correlation statistic showing a negative correlation with the number of son in first two live births with fertility, at the same time showing a positive correlation with number of daughter in the first two live births. So, it is clear that fertility is positively influenced with the increased number of daughters in first two live births and fertility is negatively influenced with the increased number of sons in first two live births.

Previous studies have linked the reason for son preference over daughter in India to number of sociocultural and economic factors [6-8]. These factors can be summarised as economic utility, sociocultural utility, and religious utility. Since Manipuri Muslims are Patrilineal society sons were 
ascribed with various social values to inherit the Patrilineal line of the family. Moreover, the economic utility of the male also cannot be ruled out as it is observed that maximum percentage of the women is confined as housewife in this population. It is male members of the society who are the main earner for living. Strong preferences of son were reported from Northern and Central India particularly Himachal Pradesh and Punjab with somewhat weaker in Southern and Western regions [5]. The effect of son preference on fertility is also reported to be weaker among the Muslims compared to Hindus in other parts of India [5]. However, we do not have any reported data on son preference in Manipur populations for comparison.

\section{Conclusion}

The present study confirms a secular trend among the Manipuri Muslims in the last decade with respect to age at menarche. The study also finds out a delayed in the age at marriage and age at first conception and reduced mean live birth and mean conception in the last one decade. The age at marriage, age at first conception, education, occupation, types of family, and PCAI have a significant effect on fertility. However, factors like age at menarche, BCM, and consanguineous marriage do not show any effect on fertility. It is also found that parents' preference for son does exist in this population like in many other Indian populations. In the process of wanting more sons, fertility is increasing. Thought the reason may be because of social and economic values attached to the males, to give a conclusive reason is out of the scope of this paper. However, since the preference for son is widespread in India for many years and many studies reported its effect on fertility in different parts of the country, the northeast region except Assam is still unreported. With the rapid urbanisation, the social values of family are also changing in this region. So, it is recommendable to reestablish new factors affecting fertility in this region in order to help curbing fertility more successfully.

\section{Conflict of Interests}

The authors declare that there is no conflict of interests regarding the publication of this paper.

\section{References}

[1] R. Bairagi and R. L. Langsten, "Sex preference for children and its implications for fertility in rural Bangladesh," Studies in Family Planning, vol. 17, no. 6, pp. 302-307, 1986.

[2] N. Das, "Sex preference and fertility behavior: a study of recent Indian data," Demography, vol. 24, no. 4, pp. 517-530, 1987.

[3] R. Mutharayappa, M. K. Choe, F. Arnold, and T. K. Roy, "Son preference and its effect on fertility in india," National Family Health Survey Subject 3, Mumbai, India, IIPS, 1997.

[4] J. Branson, "Son preference in the context of fertility decline: limits to new constructions of gender and kinship in Nepal," Studies in Family Planning, vol. 41, no. 2, pp. 89-98, 2010.
[5] S. Chaudhuri, "The desire for sons and excess fertility: a household-level analysis of parity progression in India," International Perspectives on Sexual and Reproductive Health, vol. 38, no. 4, pp. 178-186, 2012.

[6] R. A. Bulatao, "Values and disvalues of children in successive childbearing decisions," Demography, vol. 18, no. 1, pp. 1-25, 1981.

[7] C. Vlassoff, "The value of sons in an Indian village: how widows see it," Population Studies, vol. 44, no. 1, pp. 5-20, 1990.

[8] D. Friedman, M. Hechter, and S. Kanazawa, "A theory of the value of children," Demography, vol. 31, no. 3, pp. 375-401, 1994.

[9] Census of India, Provisional Population Totals, Paper 1 of 2001, Registrar General and Census Commissioner, Government of India, New Delhi, India, 2001.

[10] M. Asghar, B. Murry, and K. N. Saraswathy, "Isonymy and repeated pairs of surnames among the Muslims of Manipur, India," HOMO-Journal of Comparative Human Biology, vol. 64, no. 4, pp. 312-316, 2013.

[11] SES-MP, Report on Socio-Economic Survey of Meitei Pangals (Manipuri Muslims), Directorate of Economic and Statistics and Directorate of Minorities and other backward classes, Government of Manipur, Imphal, India, 2004.

[12] SRS, Sample Registration System Bulletin, vol. 44, Registrar General, India, 2009.

[13] B. Choudhury and M. Devi, "Fertility differentials in Manipur: a study on the meiteis and the muslims," Journal of Human Ecology, vol. 8, pp. 51-59, 1997.

[14] S. J. Singh, "Ethnic variation in fertility patterns among four communities of Manipur," Journal of Human Ecology, vol. 20, pp. 1-9, 2006.

[15] R. P. Srivastava and M. Goswami, "The menarcheal age of assamese girls," Anthropologist, vol. 15, pp. 57-60, 1968.

[16] A. E. Abelson, "Altitude and fertility, Human Biology, vol. 48, no. 1, pp. 83-91, 1976.

[17] C. R. M. Bangham and J. M. Sacherer, "Fertility of nepalese sherpas at moderate altitudes: comparison with high-altitude data," Annals of Human Biology, vol. 7, no. 4, pp. 323-330, 1980.

[18] R. Chakravarti, People of Manipur: Anthropogenetic Study of Four Manipur Population Groups, B.R. Publishing, Delhi, India, 1986.

[19] H. Raj, Fundamentals of Demography, Surjeet Publication, Delhi, India, 2006.

[20] N. S. Rao, "Pattern of income distribution and fertility levels with special references to India," Journal of Family Welfare, vol. 23, pp. 63-84, 1976.

[21] B. Mukhopadhyay, "A comparative microdemographic study of two communities in coastal Midnapore district, West Bengal," Journal of Biosocial Science, vol. 13, no. 4, pp. 479-489, 1981.

[22] J. B. Wyon and J. E. Gordon, The Khana sSudy. Population Problem in Rural Punjab, Harvard University Press, Cambridge, UK, 1971.

[23] K. N. Saraswathy, A. M. Elizabeth, M. P. Sachdeva, and A. K. Kalla, "Fertility and the influencing factors among the Kolams," Anthropologist, vol. 3, no. 1, pp. 73-74, 2001. 

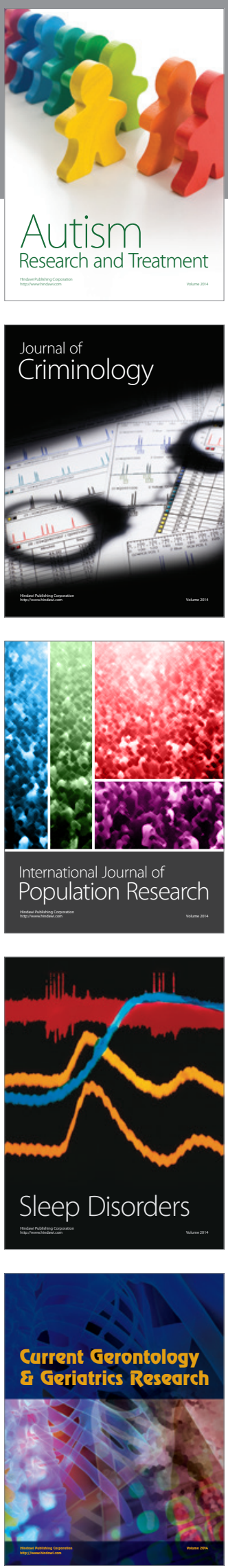
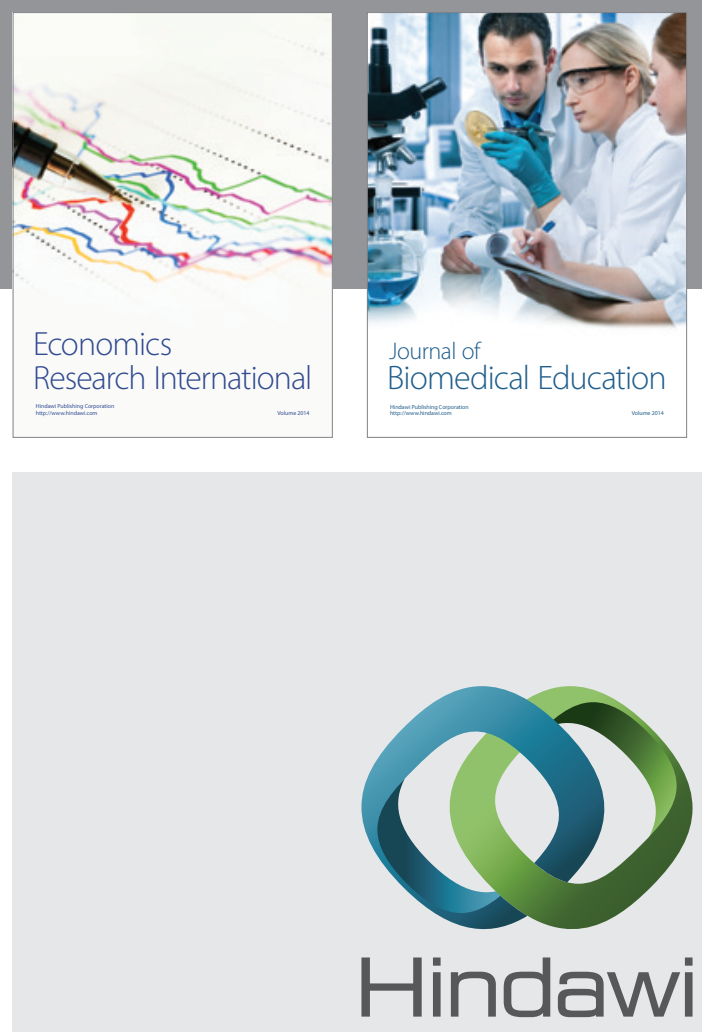

Submit your manuscripts at

http://www.hindawi.com
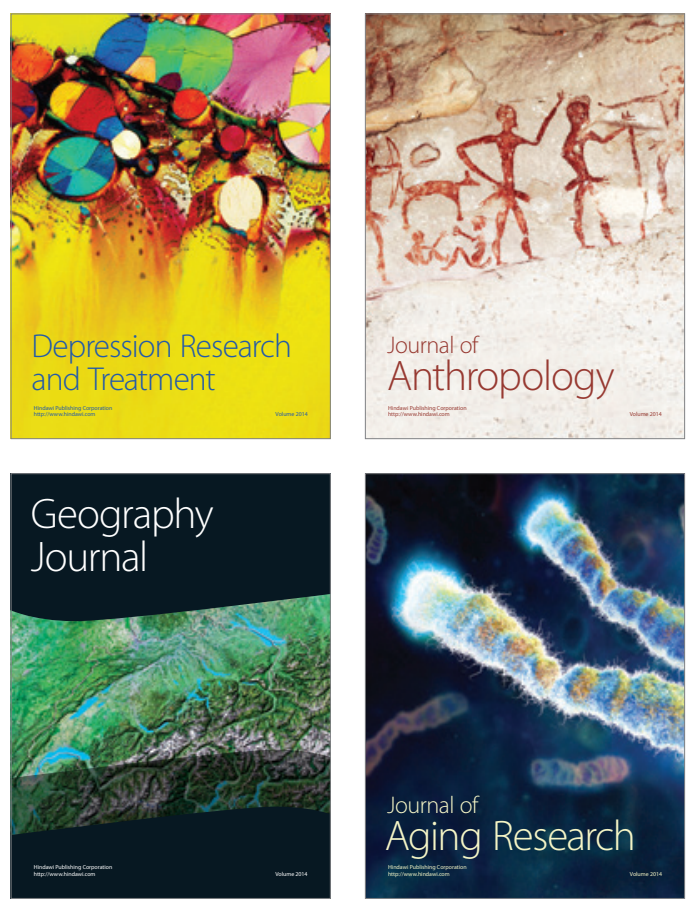
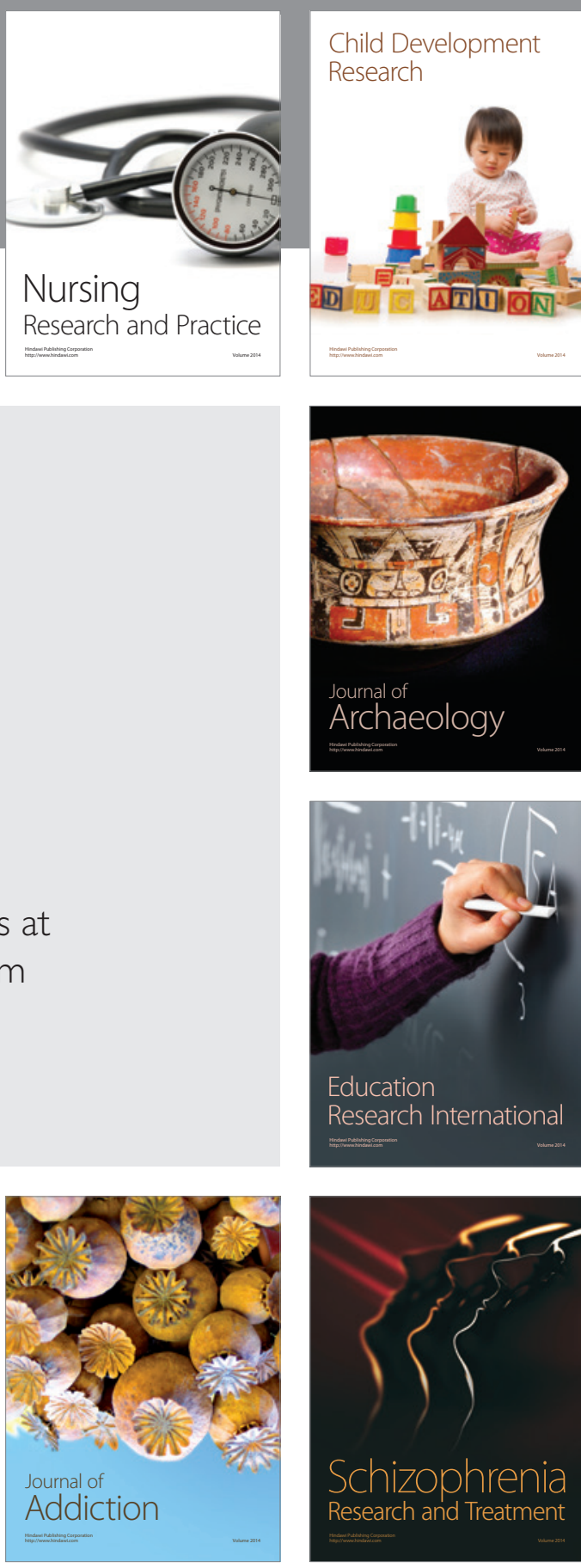

(D)
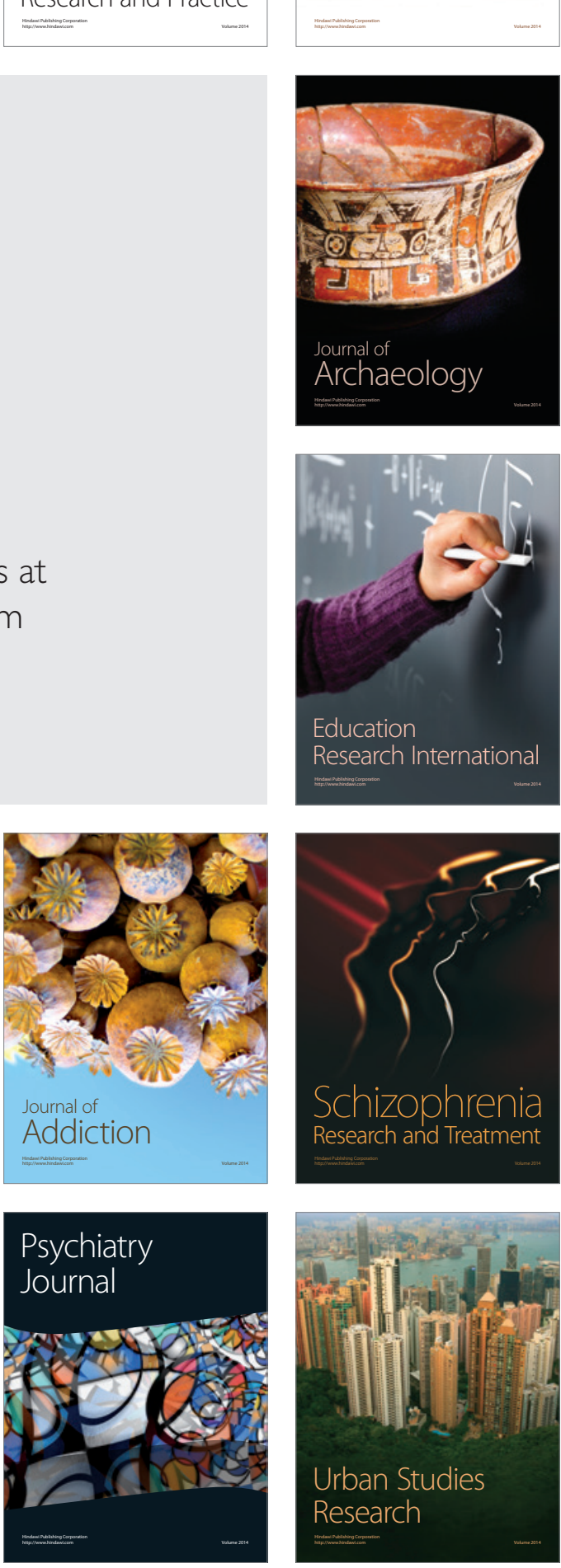